\title{
Resonance phenomenon of strain waves in helical compression springs
}

\author{
Anis Hamza a , SAmi Ayadi And Ezzeddine Hadj-Tä̈EB
}

Laboratory of Applied Fluid Mechanics and Modelling, National Engineering School of Sfax, BP. 1173, 3038 Sfax, Tunisia

Received 13 December 2012, Accepted 11 July 2013

\begin{abstract}
In this study, vibration of helical compression springs, excited axially, is discussed. The mathematical formulation of the dynamic behavior of the springs is composed of a system of four partial differential equations of first order hyperbolic type, which are the equations of momentum and the laws of constitution. The principle unknown variables are angular and axial deformations and velocities. In small deformations, the coefficients of the equation system are constant and the model describes the linear dynamic behavior of coil springs. The impedance method is applied to calculate the frequency spectrum and to study the natural frequency response. The study takes into account the dynamic coupling between the axial and angular waves due to the effects of Poisson's ratio. The results show two fundamental frequencies corresponding to the two wave speeds: fast angular waves and slow axial waves. The numerical resolution is performed by the conservative finite difference scheme of Lax-Wendroff and the finite element method. The results were used to analyze the evolution in time of deformations and velocities in different sections of the spring due to a sinusoidal excitation of the axial velocity applied at the end of the spring and to show the effect of the interaction between the axial and angular waves. These results clearly show the resonance and other phenomena related to wave propagations such as wave reflections and beat.
\end{abstract}

Key words: Helical compression spring / impedance method / method of Lax-Wendroff / finite element method / resonance and beat phenomena / Poisson coupling

Résumé - Phénomène de résonance des ondes de déformation dans les ressorts hélicoïdaux de compression. Dans cette étude, les vibrations des ressorts hélicoïdaux de compression, excités axialement, sont examinées. La formulation mathématique du comportement dynamique est constituée d'un système de quatre équations aux dérivées partielles d'ordre un de type hyperbolique. Les inconnues principales sont les déformations et les vitesses axiales et angulaires. En petites déformations, les coefficients du système d'équations sont constants et le modèle décrit le comportement dynamique linéaire des ressorts hélicoïdaux. La méthode des impédances est appliquée pour déterminer le spectre des fréquences propres et étudier la réponse fréquentielle. L'étude tient compte du couplage dynamique entre les ondes axiales et angulaires dû aux effets du coefficient de Poisson. Les résultats font apparaitre deux fréquences fondamentales qui correspondent aux deux célérités : des ondes angulaires rapides et des ondes axiales lentes. La résolution numérique est effectuée par la méthode des différences finies conservatives de Lax-Wendroff et la méthode des éléments finis. Les résultats obtenus ont permis d'analyser l'évolution, dans le temps, des déformations et des vitesses en différentes sections du ressort suite à des excitations sinusoïdales de la vitesse axiale à l'extrémité du ressort et de montrer l'effet de l'interaction entre les ondes axiales et angulaires. Ces résultats montrent bien le phénomène de résonance et d'autres phénomènes liés à la propagation des ondes stationnaires comme les phénomènes de réflexions d'ondes et de battement.

Mots clés : Ressort hélicoïdal de compression / méthode d'impédance / méthode de Lax-Wendroff / méthode des éléments finis / phénomènes de résonance et battement / couplage de Poisson

\section{Introduction}

The springs are elastic elements very widespread in a variety of machinery and equipment [1]. The main role of the springs is to absorb energy and shock, apply forces and

${ }^{a}$ Corresponding author: anis7amza@gmail.com torques, to support moving masses, etc. Helical springs are important mechanical components in many industrial applications [2]. According to different types of loading applied, the coil springs can be classified into three categories: compression springs, tension springs and torsion springs and they are usually circular or square section. 


\section{Nomenclature and Symbols}

\begin{tabular}{|c|c|c|c|}
\hline$C$ & Wave velocity $\left(\mathrm{m} \cdot \mathrm{s}^{-1}\right)$ & $U_{x}$ & Spatial component of the axial deformation (m) \\
\hline$\omega$ & Pulsation (rd.s $\left.{ }^{-1}\right)$ & $V_{x}$ & Spatial component of the angular deformation (rd) \\
\hline$C_{f}$ & Rapid angular wave celerity $\left(\mathrm{m} . \mathrm{s}^{-1}\right)$ & $U_{t}$ & Spatial component of the axial velocity $\left({\left.\mathrm{m} . \mathrm{s}^{-1}\right)}^{1}\right.$ \\
\hline$C_{s}$ & Celerity of slow axial waves $\left(\mathrm{m} \cdot \mathrm{s}^{-1}\right)$ & $V_{t}$ & Space component of the angular velocity $\left(\mathrm{rd} . \mathrm{s}^{-1}\right)$ \\
\hline$E$ & Young's modulus (GPa) & $\overline{u_{x}}$ & Mean component of axial deformation (m) \\
\hline$G$ & Shear modulus (GPa) & $\overline{v_{x}}$ & Mean component of angular deformation (rd) \\
\hline$v$ & Poisson's ratio & $\overline{u_{t}}$ & Mean component of axial velocity $\left(\mathrm{m} . \mathrm{s}^{-1}\right)$ \\
\hline$F$ & Axial force $(\mathrm{N})$ & $\overline{v_{t}}$ & Mean component of angular velocity ( ${\left.\mathrm{rd} . \mathrm{s}^{-1}\right)}^{-1}$ \\
\hline$T$ & Axial torque $(\mathrm{mN})$ & $u_{x}{ }^{\prime}$ & Oscillatory component of axial deformation (m) \\
\hline$h$ & Height of the spring $(\mathrm{m})$ & $v_{x}{ }^{\prime}$ & Oscillatory component of angular deformation (rd) \\
\hline$m$ & Elemental mass of the spring $(\mathrm{kg})$ & $u_{t}^{\prime}$ & Oscillatory component of axial velocity $\left(\mathrm{m} . \mathrm{s}^{-1}\right)$ \\
\hline$M$ & Total mass of the spring $(\mathrm{kg})$ & $v_{t}^{\prime}$ & Oscillatory component of angular velocity $\left(\mathrm{rd}_{\mathrm{s}} \mathrm{s}^{-1}\right)$ \\
\hline$n$ & Number of turns & $u_{t 0}$ & Amplitude of the sinusoidal excitation $\left(\mathrm{m} . \mathrm{s}^{-1}\right)$ \\
\hline$r$ & Radius of the coils (m) & $\alpha$ & Angle of the helix (rd) \\
\hline$r_{f}$ & Wire radius $(\mathrm{m})$ & $\delta$ & Radial expansion $(\mathrm{m})$ \\
\hline$x$ & Axial coordinate $(\mathrm{m})$ & $\Delta$ & Static elongation $(\mathrm{m})$ \\
\hline$t$ & Time (s) & $\theta$ & Static rotation $(\mathrm{rd})$ \\
\hline$I$ & Second moment $\left(\mathrm{m}^{4}\right)$ & $N$ & Number of sections \\
\hline$J$ & Polar moment $\left(\mathrm{m}^{4}\right)$ & $\Delta x$ & Space division $\Delta x=h / N(\mathrm{~m})$ \\
\hline$\varphi$ & Rotation angle of the spring (rd) & $\Delta t$ & Time division $(\mathrm{s})$ \\
\hline$u$ & Axial displacement & $Y$ & Unknown vector \\
\hline$v$ & Angular displacement & $F$ & Vector function $\mathrm{Y}$ \\
\hline \multirow[t]{2}{*}{$u_{x}$} & Axial strain $(\mathrm{m})$ & $H$ & Vector function $\mathrm{Y}$ \\
\hline & $u_{x}=\varepsilon=\partial u / \partial x$ & $B$ & Matrix function \\
\hline \multirow[t]{2}{*}{$v_{x}$} & Angular deformation (rd) & $B^{-1}$ & Inverse matrix of $\mathrm{B}$ \\
\hline & $v_{x}=\beta=\partial v / \partial x=r \partial \varphi / \partial x$ & $\lambda$ & Eigenvalues of the matrix $\mathrm{B}$ \\
\hline \multirow[t]{2}{*}{$u_{t}$} & Axial velocity $\left(\mathrm{m} . \mathrm{s}^{-1}\right)$ & $i, j, k$ & Coordinates of any grid point \\
\hline & $u_{t}=\partial u / \partial t$ & $\delta t$ & Time step (s) \\
\hline \multirow[t]{2}{*}{$v_{t}$} & Angular velocity (rd.s $\left.{ }^{-1}\right)$ & $Z_{k}$ & Mechanical impedances \\
\hline & $v_{t}=\partial v / \partial t=r \partial \varphi / \partial t$ & $A$ & Matrix solution \\
\hline$T$ & Function of $t$ only & $D$ & Determinant \\
\hline
\end{tabular}

Several accidents have been explained by different forms of resonance oscillations of the springs. For this reason, the frequency study must be carefully done.

Resonance is a phenomenon that occurs when the spring is excited by a periodic signal whose frequency is equal to the natural frequency. This phenomenon may be initiated very gradually and that builds up a steadyoscillatory regime in real situations. Moreover, a beating of a transient nature develops when the period of the excitation is not fundamental or harmonic.

Love [3] developed the equations to study the static response of helical springs subjected to large deformations. Given their important role, modeling the behavior of the springs was a very interesting objective in research work in dynamic. Stokes [4] investigated the case of a helical spring subjected to sudden shock loads, significant vibration can occur there. Gironnet and Louradour [5] determined the natural frequencies of helical springs. Various numerical and analytical methods were applied to determine the natural frequencies of resonance of the spring. These include for example; the method of transfer matrix [6], the formulation of the dynamic stiffness [7] and the pseudo spectral method [8]. Becker et al. [9] determined the resonance frequencies of a helical spring subjected to an axial load of static compression using the method of transfer matrix. Jiang et al. [10] studied the forced vibration and wave propagation in helical springs. They based their study on the method of Laplace transform to find an analytical solution in the form of a numeric sequence that describes the vibrations along the spring.

In this paper, we study the numerical propagation of elastic waves in a helical spring following a sinusoidal excitation of the axial velocity. The analytical and numerical models describing wave propagation, in the case of gradual excitations in time, have been prepared by Sinha and Costello [11]. The mathematical model is based on those established by Phillips and Costello [12]. The strain evolutions, in different sections of the spring, due to an excitation of the instantaneous velocity, are studied. The impedance method is applied to the mathematical model consisting of four partial differential equations of order one. The frequency spectra are shown in impedance diagrams. The numerical solution is carried out by the finite difference method of Lax-Wendroff and finite element method. The effect of dynamic coupling, result of Poisson's ratio, between axial and angular waves in the spring 
(1)
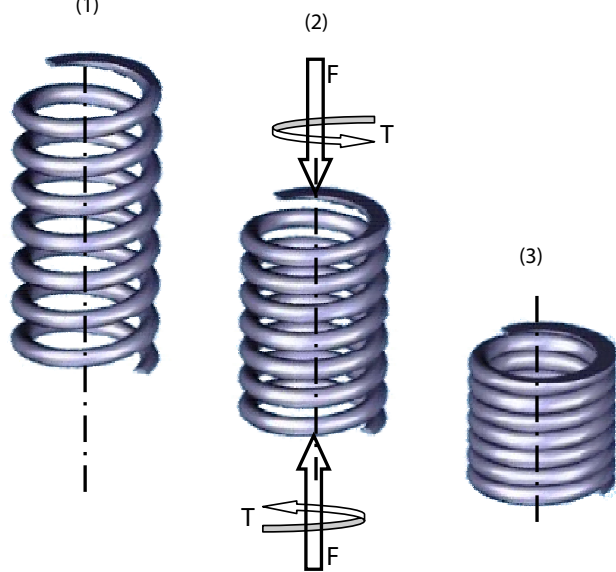

Fig. 1. Static deformation of a helical compression spring.

is studied. The results were used to examine the evolution of angular and axial strains function of time at special points of the spring to different vibration frequencies and to show concepts related to the wave propagation phenomena such as resonance and beat.

\section{Mathematical formulation}

The mathematical model representing the equations of the wave propagation in the helical springs, is obtained by the application of the theory of dimensional analysis, the general theory of bending and twisting of thin rods and the elementary strength of materials formulas to an element of the spring between two sections $x$ and $x+d x$ submitted to axial force $F$ and torque $T$ (see Figs. 1-3). This leads to the following system [13]:

$$
\begin{aligned}
\frac{\partial u_{t}}{\partial t} & =a \frac{\partial u_{x}}{\partial x}+b \frac{\partial v_{x}}{\partial x} \\
\frac{\partial v_{t}}{\partial t} & =b \frac{\partial u_{x}}{\partial x}+c \frac{\partial v_{x}}{\partial x} \\
\frac{\partial u_{x}}{\partial t} & =\frac{\partial u_{t}}{\partial x} \\
\frac{\partial v_{x}}{\partial t} & =\frac{\partial v_{t}}{\partial x}
\end{aligned}
$$

This model is a system of four first order partial differential equations of hyperbolic type. It takes into account all the four unknowns $u_{t}, u_{x}, v_{t}$ and $v_{x}$ that depend on the abscissa $x$ and time $t$, including the dynamic coupling between the axial and angular waves.

In the case of linear behavior and when the strains are small, i.e. $\left|u_{x}\right| \ll 1$ and $\left|v_{x}\right| \ll 1$, the coefficients appearing in equations (1a) to (1d) are defined by:

$$
\begin{aligned}
a & =\frac{E I h}{M r^{2}}\left(1-\frac{v}{1+v} \cos ^{2} \alpha\right) \sin \alpha \\
b & =-\frac{E I h}{M r^{2}} \frac{v}{1+v} \sin ^{2} \alpha \cos \alpha \\
c & =\frac{E I h}{M r^{2}}\left(1-\frac{v}{1+v} \sin ^{2} \alpha\right) \sin \alpha
\end{aligned}
$$

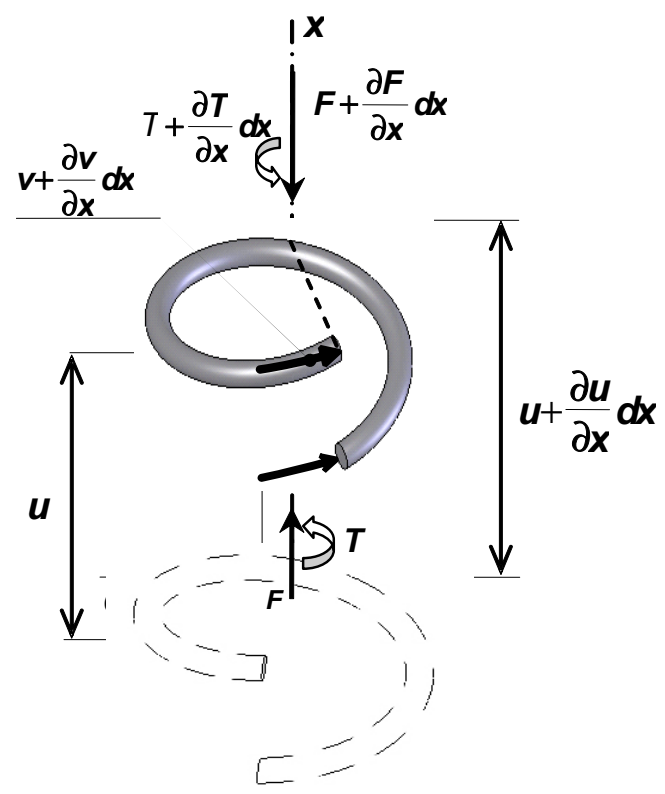

Fig. 2. Spring element.

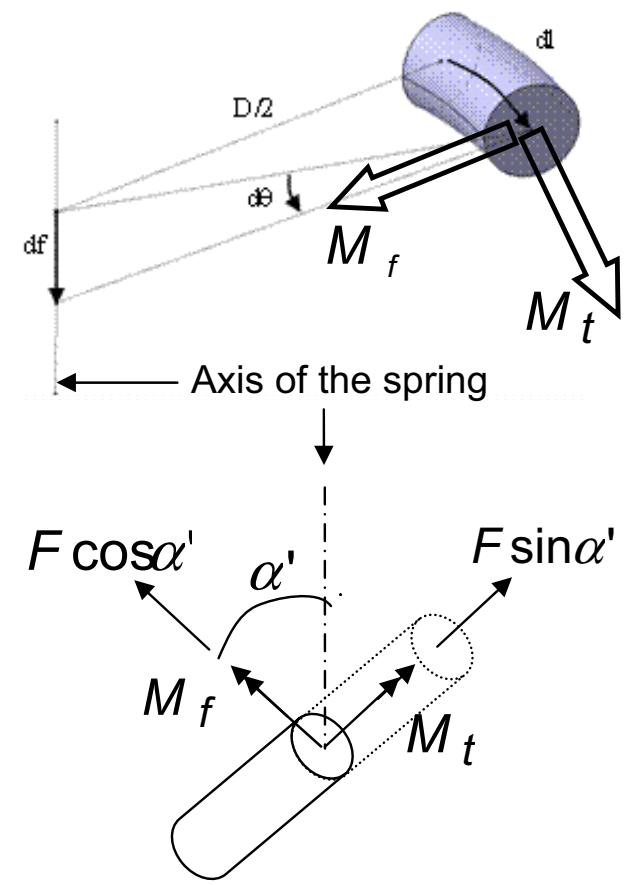

Fig. 3. Directions of the forces applied to the section of a helical spring.

\section{Numerical solution}

\subsection{Lax-Wendroff method}

The numerical solution of the problem for hyperbolic partial differential equations described by $\{(1 \mathrm{a})$ to $(1 \mathrm{~d})\}$ can be obtained by the method of Lax-Wendroff [14] which is applied to transform the system of partial differential equations into a system of finite difference equations. The method of Lax-Wendroff scheme is a three-point explicit accuracy method of two-steps: the 


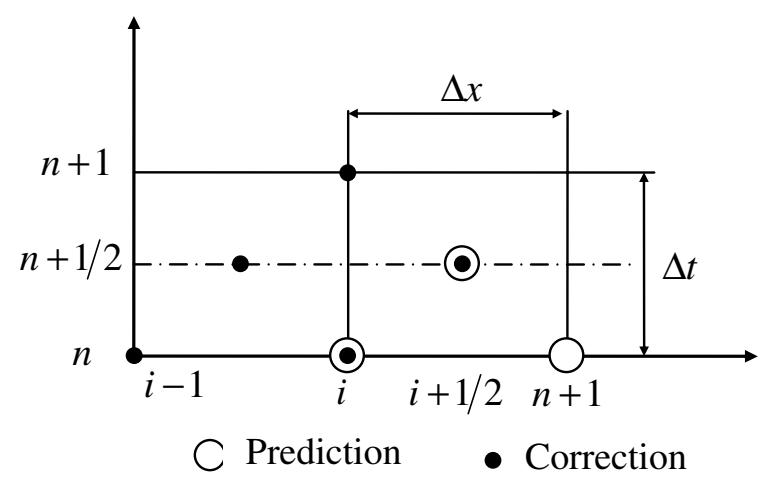

Fig. 4. Lax-Wendroff scheme.

prediction and the correction. It is easily applied to the resolution of conservative formulations [15]. The conservative formulation is written as:

$$
\frac{\partial Y}{\partial t}+\frac{\partial G(Y)}{\partial x}=H(Y)
$$

$F$ and $H$ are two vector functions of the unknown vector $Y$ defined by:

$$
Y=\left(\begin{array}{l}
u_{x} \\
v_{x} \\
u_{t} \\
v_{t}
\end{array}\right), \quad G=\left(\begin{array}{l}
u_{t} \\
v_{t} \\
a u_{x}+b v_{x} \\
b u_{x}+c v_{x}
\end{array}\right) \text { and } H=0
$$

The spring is divided into $N$ equal elements of length $\Delta x$. Indeed, with the notations of Figure 4, we can write: $Y_{i}^{k}=Y[(i-1) \Delta x, k \Delta t]$ and $G_{i}^{k}=G\left(Y_{i}^{k}\right)$.

Moreover, the unknown vector $Y(x, t+\Delta t)$ can be approximated with the first terms of its Taylor expansion about $t$, as:

$$
Y(x, t+\delta t)=Y(x, t)+\delta t \frac{\partial Y}{\partial t}
$$

Then, by introducing the physical laws of the dynamic response given by equation (3), that is:

$$
\frac{\partial Y}{\partial t}=-\frac{\partial G(Y)}{\partial x}
$$

we obtain the finite difference form:

$$
Y(x, t+\delta t)=Y(x, t)-\delta t \frac{\partial G}{\partial x}
$$

Following the techniques described by Lerat and Peyret [16], the two-steps Lax-Wendroff scheme [17] used on conservative equation (3), for any grid point $(i, k+1)$, can be deduced from (6) and are as follows:

For the first step or prediction phase [instant $(k+$ $1 / 2) \Delta t]$ :

$$
Y_{i+1 / 2}^{k+1 / 2}=\frac{1}{2}\left(Y_{i+1}^{k}+Y_{i}^{k}\right)-\frac{\Delta t}{2 \Delta x}\left(G_{i+1}^{k}-G_{i}^{k}\right)
$$

And for the second step or correction phase [instant $(k+$ 1) $\Delta t]$ :

$$
Y_{i}^{k+1}=Y_{i}^{k}-\frac{\Delta t}{\Delta x}\left(G_{i+1 / 2}^{k+1 / 2}-G_{i-1 / 2}^{k+1 / 2}\right)
$$

The $\lambda$ are the eigenvalues of the matrix $B$ which is such that: $\frac{\partial G(Y)}{\partial x}=B \frac{\partial Y}{\partial x}$.

Under these conditions:

$$
\begin{aligned}
B= & -\left[\begin{array}{llll}
0 & a & 0 & b \\
1 & 0 & 0 & 0 \\
0 & b & 0 & c \\
0 & 0 & 1 & 0
\end{array}\right] \\
& \text { and } \operatorname{det}(B-\lambda I)=\lambda^{4}-(a+c) \lambda^{2}+\left(a c-b^{2}\right)
\end{aligned}
$$

With $\mu=1 / \lambda$, we can write:

$$
\left(a c-b^{2}\right) \mu^{4}-(a+c) \mu^{2}+1=0
$$

which admits four roots $\left\{-C_{f},-C_{s}, C_{s} C_{f}\right\}$, where, $C_{f}$ is the rapid angular wave celerity defined in the spring by:

$$
C_{f}=\sqrt{\frac{(a+c)+\sqrt{(a-c)^{2}+4 b^{2}}}{2}}=\sqrt{\frac{E I h}{M r^{2}} \sin \alpha}
$$

and $C_{s}$ is the slow axial wave celerity defined by:

$$
C_{s}=\sqrt{\frac{(a+c)-\sqrt{(a-c)^{2}+4 b^{2}}}{2}}=\sqrt{\frac{E I h}{M r^{2}} \frac{\sin \alpha}{1+v}}
$$

\subsection{Finite element method}

For the present work, the finite element method, based on the Galerkin formulation [18-20], was used. The spring is divided into $n$ equal elements with two nodes and four degrees of freedom per node $\left(u_{t}, u_{x}, v_{t}, v_{x}\right)$.

For each node $i$, the adopted shape functions $N_{i}^{(j)}(x)$ are the linear ones of the roof form plotted in Figure 5. These functions are defined by:

$$
N_{i}^{(j)}(x)=\left\{\begin{array}{cc}
\frac{x-x_{i-1}}{x_{i}-x_{i-1}} & \text { if } \quad j=i-1 \\
\frac{x-x_{i+1}}{x_{i+1}-x_{i}} & \text { if } \quad j=i \\
0 \quad \text { if } j \neq i-1 & \text { and } j \neq i
\end{array}\right.
$$

$x_{i}$ and $x_{i+1}$ indicates the node abscissa bounding the element $(i)$.

As it can be seen, $N_{i}^{(j)}=0$ for all element $(j)$ not bounded by node $i$.

The variables $u_{t}, u_{x}, v_{t}$ and $v_{x}$ and the non constant coefficients $a, b$ and $c$ are assumed to be linearly variable with $x$ in each element $i$, e.g.:

$$
u_{t}=N_{i}^{(i)} u_{t_{i}}+N_{i+1}^{(i)} u_{t_{i+1}} \quad a=N_{i}^{(i)} a_{i}+N_{i+1}^{(i)} a_{i+1}
$$




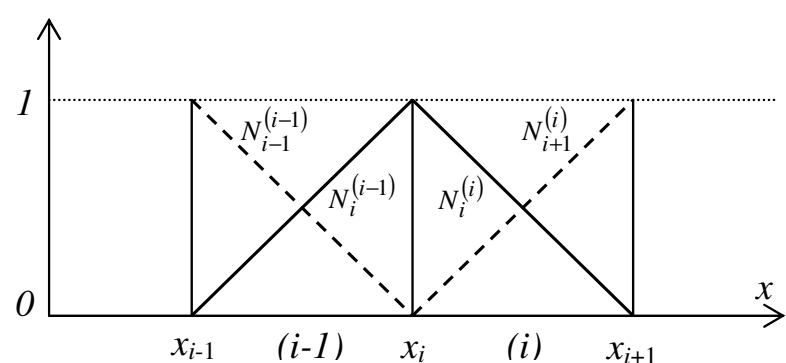

Fig. 5. Functions of linear interpolation.

The Galerkin procedure, as applied to equations $\{(1 \mathrm{a})$ to $(1 \mathrm{~d})\}$ using finite elements, requires that [21]:

$$
\begin{aligned}
& \sum_{j} \int_{L_{j}} N_{i}^{(j)}\left[\frac{\partial u_{t}}{\partial t}-a \frac{\partial u_{x}}{\partial x}-b \frac{\partial v_{x}}{\partial x}\right] \mathrm{d} x=0 \\
& \sum_{j} \int_{L_{j}} N_{i}^{(j)}\left[\frac{\partial u_{x}}{\partial t}-\frac{\partial u_{t}}{\partial x}\right] \mathrm{d} x=0 \\
& \sum_{j} \int_{L_{j}} N_{i}^{(j)}\left[\frac{\partial v_{t}}{\partial t}-b \frac{\partial u_{x}}{\partial x}-c \frac{\partial v_{x}}{\partial x}\right] \mathrm{d} x=0 \\
& \sum_{j} \int_{L_{j}} N_{i}^{(j)}\left[\frac{\partial v_{x}}{\partial t}-\frac{\partial v_{t}}{\partial x}\right] \mathrm{d} x=0
\end{aligned}
$$

In which $L_{j}=\Delta x$ is the length of the spring element $(j)$.

Note that the sums of integrals in equations (12a) to $(12 \mathrm{~d})$ are equivalently given as:

$$
\alpha \int_{x_{i-1}}^{x_{i}} N_{i}^{(i-1)}[\quad] \mathrm{d} x+\beta \int_{x_{i}}^{x_{i+1}} N_{i}^{(i)}[\quad] \mathrm{d} x=0
$$

In which $\alpha=\beta=1$ for all interior nodes, $\alpha=0$ and $\beta=1$ for the first node $i=1$ and $\alpha=1$ and $\beta=0$ for $i=n+1$, the last node point.

For interior node points:

$$
\begin{aligned}
& a_{i-1 / 3}\left(u_{x_{i-1}}-u_{x_{i}}\right)+b_{i-1 / 3}\left(v_{x_{i-1}}-v_{x_{i}}\right) \\
& -\Delta x\left(\frac{\partial u_{t_{i-1}}}{\partial t}-2 \frac{\partial u_{t_{i}}}{\partial t}\right)+a_{i+1 / 3}\left(u_{x_{i}}-u_{x_{i+1}}\right) \\
& +b_{i+1 / 3}\left(v_{x_{i}}-v_{x_{i+1}}\right)-\Delta x\left(\frac{\partial u_{t_{i}}}{\partial t}-2 \frac{\partial u_{t_{i+1}}}{\partial t}\right)=0
\end{aligned}
$$

$$
\begin{aligned}
\frac{\Delta x}{6} \frac{\partial u_{x_{i-1}}}{\partial t}+\frac{2 \Delta x}{3} \frac{\partial u_{x_{i}}}{\partial t} & +\frac{\Delta x}{6} \frac{\partial u_{x_{i+1}}}{\partial t} \\
& -\frac{1}{2}\left(u_{t_{i+1}}-u_{t_{i-1}}\right)=0
\end{aligned}
$$

$$
\begin{aligned}
& b_{i-1 / 3}\left(u_{x_{i-1}}-u_{x_{i}}\right)+c_{i-1 / 3}\left(v_{x_{i-1}}-v_{x_{i}}\right) \\
& -\Delta x\left(\frac{\partial v_{t_{i-1}}}{\partial t}-2 \frac{\partial v_{t_{i}}}{\partial t}\right)+b_{i+1 / 3}\left(u_{x_{i}}-u_{x_{i+1}}\right) \\
& +c_{i+1 / 3}\left(v_{x_{i}}-v_{x_{i+1}}\right)-\Delta x\left(\frac{\partial v_{t_{i}}}{\partial t}-2 \frac{\partial v_{t_{i+1}}}{\partial t}\right)=0
\end{aligned}
$$

$$
\begin{aligned}
\frac{\Delta x}{6} \frac{\partial v_{x_{i-1}}}{\partial t}+\frac{2 \Delta x}{3} \frac{\partial v_{x_{i}}}{\partial t} & +\frac{\Delta x}{6} \frac{\partial v_{x_{i+1}}}{\partial t} \\
& -\frac{1}{2}\left(v_{t_{i+1}}-v_{t_{i-1}}\right)=0
\end{aligned}
$$

In which $a_{i \pm 1 / 3}=2 a_{i}+a_{i \pm 1}, b_{i \pm 1 / 3}=2 b_{i}+b_{i \pm 1}, c_{i+1 / 3}=$ $2 c_{i}+c_{i \pm 1}$ and $\Delta x=x_{i}-x_{i-1}=x_{i+1}-x_{i}$ is the space step size.

Since $a_{i}, b_{i}$ and $c_{i}$ are functions of $u_{x_{i}}$ and $v_{x_{i}}$, equations (14a) to (14d) form a coupled set of non-linear ordinary differential equations in time. In the linear case $a_{i}=a, b_{i}=b$ and $c_{i}=c$ are constants and $a_{i \pm 1 / 3}=3 a$, $b_{i \pm 1 / 3}=3 b$ and $c_{i \pm 1 / 3}=3 c$.

To complete the development, it is necessary to repeat the preceding steps for the boundary equations. Application of (13) to equations (1a) to (1d) for $i=1$ and $i=n+1$ gives:

$$
\begin{gathered}
a_{1+1 / 3} \frac{u_{x_{2}}-u_{x_{1}}}{\Delta x}+b_{1+1 / 3} \frac{v_{x_{2}}-v_{x_{1}}}{\Delta x} \\
-\Delta x\left(2 \frac{\partial u_{t 1}}{\partial t}+\frac{\partial u_{t 2}}{\partial t}\right)=0 \\
3\left(u_{t 2}-u_{t 1}\right)-\Delta x\left(2 \frac{\partial u_{x 1}}{\partial t}+\frac{\partial u_{x 2}}{\partial} t\right)=0
\end{gathered}
$$

$$
\begin{aligned}
& b_{1+1 / 3} \frac{u_{x 2}-u_{x 1}}{\Delta x}+ c_{1+1 / 3} \frac{v_{x 2}-v_{x 1}}{\Delta x} \\
&-\Delta x\left(2 \frac{\partial v_{t 1}}{\partial t}+\frac{\partial v_{t 2}}{\partial t}\right)=0 \\
& 3\left(v_{t 2}-v_{t 1}\right)-\Delta x\left(2 \frac{\partial v_{x 1}}{\partial t}+\frac{\partial v_{x 2}}{\partial t}\right)=0
\end{aligned}
$$

$$
\begin{array}{r}
a_{n+1 / 3}\left[u_{x n+1}-u_{x n}\right]+b_{n+1 / 3}\left[v_{x n+1}-v_{x N}\right] \\
-\Delta x\left[\frac{\partial u_{t n}}{\partial t}+2 \frac{\partial u_{t n+1}}{\partial t}\right]=0 \\
\Delta x\left(\frac{\partial u_{x n}}{\partial t}+2 \frac{\partial u_{x n+1}}{\partial t}\right)-3\left(u_{t n+1}-u_{t n}\right)=0
\end{array}
$$

$$
\begin{aligned}
& b_{n+1 / 3}\left(u_{x n+1}-\right.\left.u_{x n}\right)+c_{n+1 / 3}\left(v_{x_{n+1}}-v_{x n}\right) \\
&-\Delta x\left(\frac{\partial v_{t} n}{\partial t}+2 \frac{\partial v_{t n+1}}{\partial t}\right)=0
\end{aligned}
$$

$$
\Delta x\left(\frac{\partial v_{x n}}{\partial t}+2 \frac{\partial v_{x n+1}}{\partial t}\right)-3\left(v_{t n+1}-v_{t n}\right)=0
$$

The final step in setting up equations (14a) to (14d) for solution is the formulation of the scheme for integration over time. A flexible and relatively simple technique involves approximate integration over a set of finite time 


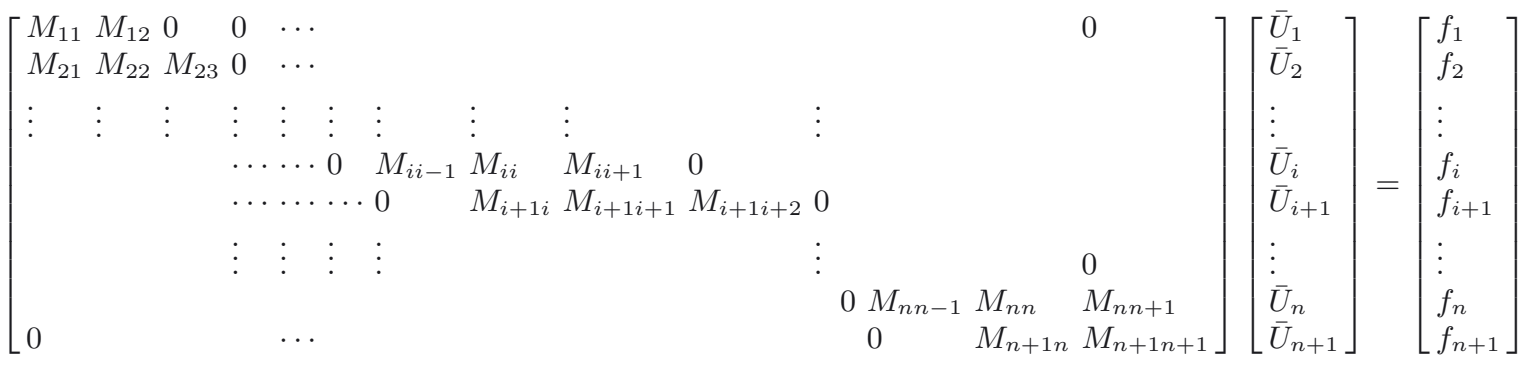

intervals. The approximation results from assuming that the variation in time for variables not in a time derivative can be accounted for by writing the variables as weighted averages over time, e.g.:

$$
\bar{u}_{t_{i}}=u_{t_{i}}^{k-1}+\theta\left(u_{t_{i}}^{k}-u_{t_{i}}^{k-1}\right)
$$

In which $\bar{u}_{t_{i}}$ is the weighted average between time levels $k-1$ and $k$; and $\theta$ is a parameter which affects the stability of the solution; $0 \leq \theta \leq 1$. As an example, the first term in equation (14a) would be written $\bar{a}_{i-(1 / 3)}\left(\bar{u}_{x_{i}}-\bar{u}_{x_{i-1}}\right)=$ $\left(2 \bar{a}_{i}+\bar{a}_{i-1}\right)\left(\bar{u}_{x_{i}}-\bar{u}_{x_{i-1}}\right)$. Semi implicit Euler method is used to integrate the time derivatives over the time step $(k-1+\theta) \Delta t$ to yield terms of the form:

$$
\frac{1}{\Delta t} \int_{(k-1) \Delta t}^{k \Delta t} \frac{\partial u_{t_{i}}}{\partial t} d t=\frac{u_{t_{i}}^{k}-u_{t_{i}}^{k-1}}{\Delta t}=\frac{\bar{u}_{t_{i}}-u_{t_{i}}^{k-1}}{\theta \Delta t}
$$

In this expression, equation (17) was used to replace $u_{t i}^{k}$.

Time integration of equations (14a) to (14d), which involves the use of equations (17) and (18), yields a set of non-linear equations that are frequently solved by using iterative algorithms.

After assembly, we obtain the non-linear matrix system:

$$
\text { See equation (19) above. }
$$

where:

$-M_{i k}$ is $(4 \times 4)$ matrix which is null if $k<i-1$ or $k>i+1$ else it depends of the unknowns of the problem $\left\{\bar{u}_{x i-1}, \bar{v}_{x i-1} \bar{u} x_{i}, \bar{v}_{x i} \bar{u}_{x i+1}, \bar{v}_{x i+1}\right\}$ at the time $(n-1+\theta) \Delta t$ and $(n-1) \Delta t$.

$-\left\{\bar{U}_{i}\right\}^{t}=\left(\bar{u}_{t_{i}}, \bar{u}_{x_{i}}, \bar{v}_{t_{i}}, \bar{v}_{x_{i}}\right)$ is the unknown vector at the node $i$ and the time $(n-1+\theta) \Delta t$.

- $f_{i}$ is a second member vector which depends of the unknowns of the problem at the time $(n-1) \Delta t$.

- $M_{11}, M_{12}, M_{n+1 n}, M_{n+1 n+1}$ are $(4 \times 4)$ matrix which depends of the boundary conditions in the nodes 1 and $n+1$.

- $f_{1}$ and $f_{n+1}$ contain the boundary conditions.

The final step in the procedure is the solution of the nonlinear matrix system (19) written as a compact form:

$$
[K(\bar{U})]\{\bar{U}\}=\{f\}
$$

where $\bar{U}$ is the solution at the time $(n-1+\theta) \Delta t$.

The solution of the system (20) is obtained using an iterative algorithm based on the Gauss substitution method [22]. In this method a succession of solutions $\left\{\bar{U}^{1}\right\},\left\{\bar{U}^{2}\right\}, \ldots\left\{\bar{U}^{m}\right\}$ is constructed. $\left\{\bar{U}^{m}\right\}$ is calculated from $\left\{\bar{U}^{m-1}\right\}$ by solving the following linear system:

$$
\left[K\left(\{\bar{U}\}^{m-1}\right)\right]\{\bar{U}\}^{m}=\{f\}, \quad m=1,2, \ldots
$$

with $\{\bar{U}\}^{0}=\{U\}^{n-1}\left(\{U\}^{n-1}\right.$ is the solution at the time $(n-1) \Delta t)$.

The process is repeated until the convergence of solution. This is obtained when $\left\|\{\bar{U}\}^{m}-\{\bar{U}\}^{m-1}\right\| \leq$ $\varepsilon\left\|\{\bar{U}\}^{m-1}\right\|$, where $\varepsilon \ll 1$.

The speeds $C_{s}$ and $C_{f}$ are used to define the time step $\Delta t=t^{k}-t^{k-1}$ from the Courant-Freidrichs- Lewy [23] stability condition for finite difference approximations of hyperbolic equations:

$$
c_{f} \frac{\Delta t}{\Delta x} \leq 1
$$

The stability and the speed of convergence depend of three parameters which are the time increment $\Delta t$, the number of finite elements $n$ and the value of $\theta$ which must satisfy the relation (22) and $\theta \geq 0.5$ [24].

When the solution $\{\bar{U}\}$ is obtained at the time $(n-1+\theta) \Delta t$, equation (17) permits us to obtain the solution $\{U\}^{n}$ at the time $n \Delta t$.

\subsection{Impedance method}

The partial differential equations considered are linear; they are solved for sinusoidal perturbations with the same frequency throughout the system. Static behavior of the variables being initially zero, $(\Delta=0$ and $\theta=0)$, the instantaneous quantities are terms of fluctuations. It is advantageous to separate the total instantaneous mechanical variables $\left(u_{x}, u_{t}, v_{x}, v_{t}\right)$ into two parts, the mean variables $\left(\bar{u}_{x}, \bar{u}_{t}, \bar{v}_{x}, \bar{v}_{t}\right)$, and the oscillatory variables $\left(u_{x}^{\prime}\right.$, $\left.u_{t}^{\prime}, v_{x}^{\prime}, v_{t}^{\prime}\right)$ so that $\left(u_{x}=\bar{u}_{x}+u_{x}^{\prime}, \ldots\right)$.

The mean variables are given by the initial conditions represented by the static deflection of the spring (see Fig. 2):

$$
\bar{u}_{x}=-\frac{\Delta}{h}, \quad \bar{u}_{t}=0, \quad \bar{v}_{x}=\frac{r \theta}{h} \text { and } \bar{v}_{t}=0
$$


Using this notation, the equations of motion (1a) to (1d) become:

$$
\begin{aligned}
\frac{\partial u_{t}^{\prime}}{\partial t}-a \frac{\partial u_{x}^{\prime}}{\partial x}-b \frac{\partial v_{x}^{\prime}}{\partial x} & =0 \\
\frac{\partial u_{x}^{\prime}}{\partial t}-\frac{\partial u_{t}^{\prime}}{\partial x} & =0 \\
\frac{\partial v_{t}^{\prime}}{\partial t}-b \frac{\partial u_{x}}{\partial x}-c \frac{\partial v_{x}^{\prime}}{\partial x} & =0 \\
\frac{\partial v_{x}^{\prime}}{\partial t}-\frac{\partial v_{t}^{\prime}}{\partial x} & =0
\end{aligned}
$$

One may solve the linearized equations of the coupled free vibration of helical springs by using the separationof-variables technique which assumes that [25]:

$$
\begin{aligned}
u_{x}^{\prime} & =u_{x}^{\prime}(x, t)=U_{x}(x) T(t), \\
u_{t}^{\prime} & =u_{t}^{\prime}(x, t)=U_{t}(x) T(t), \\
v_{x}^{\prime} & =v_{x}^{\prime}(x, t)=V_{x}(x) T(t), \\
v_{t}^{\prime} & =v_{t}^{\prime}(x, t)=V_{t}(x) T(t)
\end{aligned}
$$

where $U_{x}(x), V_{x}(x), U_{t}(x)$ and $V_{t}(x)$ are nontimevarying complex functions of strains and velocities and $T$ is a function of $t$ only.

The impedance method consists in solving the equations of system (8) by the method of separation of variables $Y(x, t)=X(x) T(t)$, where $X^{t}(x)=$ $\left(U_{x} V_{x} U_{t} V_{t}\right)$.

By restricting the solution for $T$ to the steadyoscillatory case, that is, by assuming a particular solution for $T$ as a harmonic oscillation, the solution can be expressed:

$$
T=C \mathrm{e}^{i \omega t}
$$

After substituting and rearranging:

$$
\frac{\mathrm{d} X}{\mathrm{~d} x}=i \omega B^{-1} X
$$

where:

$$
\begin{aligned}
X(x)= & {\left[\begin{array}{l}
U_{x} \\
V_{x} \\
U_{t} \\
V_{t}
\end{array}\right] \text { and } B=\left[\begin{array}{llll}
0 & 0 & 1 & 0 \\
0 & 0 & 0 & 1 \\
a & b & 0 & 0 \\
b & c & 0 & 0
\end{array}\right] } \\
& =\left[\begin{array}{llll}
0 & 0 & 1 & 0 \\
0 & 0 & 0 & 1 \\
c_{s}^{2}\left(1+v \sin ^{2} \alpha\right) & -c_{s}^{2} v \sin \alpha \cos \alpha & 0 & 0 \\
-c_{s}^{2} v \sin \alpha \cos \alpha & c_{s}^{2}\left(1+v \cos ^{2} \alpha\right) & 0 & 0
\end{array}\right]
\end{aligned}
$$

The solution of equation (26) can be written [26]:

$$
X(x)=\mathrm{e}^{i \omega x B^{-1}} X(0)=[A(x)] X(0)
$$

The inverse of the matrix $B$ can be easily found by the Gauss' elimination method:

$B^{-1}=\left[\begin{array}{llll}0 & 0 & \frac{c}{a c-b^{2}} & \frac{-b}{a c-b^{2}} \\ 0 & 0 & \frac{-b}{a c-b^{2}} & \frac{a}{a c-b^{2}} \\ 1 & 0 & 0 & 0 \\ 0 & 1 & 0 & 0\end{array}\right]=\left[\begin{array}{lllll}0 & 0 & \frac{1+v \cos ^{2} \alpha}{C_{f}^{2}} & \frac{v \sin \alpha \cos \alpha}{C_{f}^{2}} \\ 0 & 0 & \frac{v \sin \alpha \cos \alpha}{C_{f}^{2}} & \frac{1+v \sin ^{2} \alpha}{C_{f}^{2}} \\ 1 & 0 & 0 & 0 \\ 0 & 1 & 0 & 0\end{array}\right]$

The eigenvalues of $B^{-1}$ are the roots of the characteristic equation:

$$
\operatorname{det}\left(B^{-1}-\lambda I\right)=\lambda^{4}-\frac{a+c}{a c-b^{2}} \lambda^{2}+\frac{1}{a c-b^{2}}=0
$$

Since $B^{-1}$ is a four-by-four matrix, then, from algebraic theory, equation (28) can be written:

$$
\begin{aligned}
X(x)= & {[A(x)] X(0)=\left[a_{0} I+a_{1}\left(i \omega x B^{-1}\right)\right.} \\
& \left.+a_{2}\left(i \omega x B^{-1}\right)^{2}+a_{3}\left(i \omega x B^{-1}\right)^{3}\right] X(0)
\end{aligned}
$$

where $a_{r}$ are defined by using the determinants: $a_{r}=\frac{D_{r}}{D}$ with:

$$
\begin{array}{r}
D=\left|\begin{array}{cccc}
1 & 1 & 1 & 1 \\
i \omega x \lambda_{1} & i \omega x \lambda_{2} & i \omega x \lambda_{3} & i \omega x \lambda_{4} \\
\left(i \omega x \lambda_{1}\right)^{2} & \left(i \omega x \lambda_{2}\right)^{2} & \left(i \omega x \lambda_{3}\right)^{2} & \left(i \omega x \lambda_{4}\right)^{2} \\
\left(i \omega x \lambda_{1}\right)^{3} & \left(i \omega x \lambda_{2}\right)^{3} & \left(i \omega x \lambda_{3}\right)^{3} & \left(i \omega x \lambda_{4}\right)^{3}
\end{array}\right| \\
=-4 v^{2} \sqrt{1+v}\left(\frac{\omega x}{c_{f}}\right)^{6}
\end{array}
$$

$D_{r}$ is obtained by replacing the elements $\left(i \omega x \lambda_{1}\right)^{r}, \ldots$, $\left(i \omega x \lambda_{4}\right)^{r}$ in $D$ by $\mathrm{e}^{i \omega x \lambda_{1}}, \ldots, \mathrm{e}^{i \omega x \lambda_{4}}$.

The eigenvalues of the matrix $B$ are $\left\{-C_{f},-C_{s}\right.$, $\left.C_{s}, C_{f}\right\}$ and those of the matrix $i x \omega B^{-1}$ are $\left\{\lambda_{1}=\right.$ $\left.-i \omega x / C_{s}, \lambda_{2}=-i \omega x / C_{f}, \lambda_{3}=i \omega x / C_{f}, \lambda_{4}=i \omega x / C_{s}\right\}$

Using a software MATHEMATICA treatment and the coefficients of the matrix $[A(x)]$ shown in equation (28) we obtain the mechanical impedances in the helical spring defined as the ratio of complex axial and angular strains to the complex axial and angular velocities as follows:

\section{See equation (33) next page.}

In practice, we are interested to the mechanical impedances at the extremity $\mathrm{S}(x=h)$ of the spring. In the case where the spring is clamped at the extremity $\mathrm{R}(x=0)$ and axially loaded at the extremity $\mathrm{S}$, the boundary conditions can be expressed (see Fig. 6):

$$
U_{t}(0)=0, V_{t}(0)=0, U_{t}(h) \neq 0, V_{t}(h)=0
$$

Impedance transfer functions are utilized to express the impedance at one point in terms of conditions at another location, usually a terminal condition. Although transfer 


$$
\begin{aligned}
& Z_{1}(x)=\frac{u_{x}^{\prime}}{u_{t}^{\prime}}=\frac{A_{11}(x) U_{x}(0)+A_{12}(x) V_{x}(0)+A_{13}(x) U_{t}(0)+A_{14}(x) V_{t}(0)}{A_{31}(x) U_{x}(0)+A_{32}(x) V_{x}(0)+A_{33}(x) U_{t}(0)+A_{34}(x) V_{t}(0)} \\
& Z_{2}(x)=\frac{v_{x}^{\prime}}{u_{t}^{\prime}}=\frac{A_{21}(x) U_{x}(0)+A_{22}(x) V_{x}(0)+A_{23}(x) U_{t}(0)+A_{24}(x) V_{t}(0)}{A_{31}(x) U_{x}(0)+A_{32}(x) V_{x}(0)+A_{33}(x) U_{t}(0)+A_{34}(x) V_{t}(0)} \\
& Z_{3}(x)=\frac{u_{x}^{\prime}}{v_{t}^{\prime}}=\frac{A_{11}(x) U_{x}(0)+A_{12}(x) V_{x}(0)+A_{13}(x) U_{t}(0)+A_{14}(x) V_{t}(0)}{A_{41}(x) U_{x}(0)+A_{42}(x) V_{x}(0)+A_{43}(x) U_{t}(0)+A_{44}(x) V_{t}(0)} \\
& Z_{4}(x)=\frac{v_{x}^{\prime}}{v_{t}^{\prime}}=\frac{A_{21}(x) U_{x}(0)+A_{22}(x) V_{x}(0)+A_{23}(x) U_{t}(0)+A_{24}(x) V_{t}(0)}{A_{41}(x) U_{x}(0)+A_{42}(x) V_{x}(0)+A_{43}(x) U_{t}(0)+A_{44}(x) V_{t}(0)}
\end{aligned}
$$

functions may be written to relate the impedance at any position $x$ in a spring to the boundary conditions, the transfer equation that relates impedance at the loaded extremity in terms of impedance at the clamped extremity is particularly useful:

$$
\begin{aligned}
& Z_{1}(h)=\frac{A_{11}(h) A_{42}(h)-A_{12}(h) A_{41}(h)}{A_{31}(h) A_{42}(h)-A_{32}(h) A_{41}(h)} \\
& \text { and } Z_{2}(h)=\frac{A_{21}(h) A_{42}(h)-A_{22}(h) A_{41}(h)}{A_{31}(h) A_{42}(h)-A_{32}(h) A_{41}(h)}
\end{aligned}
$$

In the case where the load is angular, one can define two other impedances at the loaded extremity:

$$
\begin{aligned}
& Z_{3}(h)=\frac{A_{11}(h) A_{32}(h)-A_{12}(h) A_{31}(h)}{A_{41}(h) A_{32}(h)-A_{42}(h) A_{31}(h)} \\
& \text { and } Z_{4}(h)=\frac{A_{21}(h) A_{32}(h)-A_{22}(h) A_{31}(h)}{A_{41}(h) A_{32}(h)-A_{42}(h) A_{31}(h)}
\end{aligned}
$$

The impedances vary with the frequency and are maximum for an infinite number of frequencies. These are the natural frequencies of the helical spring system and they correspond to the zero of the impedance denominator that is the zero of the expression: $A_{41}(h) A_{32}(h)-$ $A_{31}(h) A_{42}(h)$.

One can verify that:

$$
\begin{aligned}
A_{41}(h) A_{32}(h)-A_{31}(h) A_{42}(h)= & c_{f} c_{s} \sin \left(\frac{\omega h}{c_{f}}\right) \\
& \times \sin \left(\frac{\omega h}{c_{s}}\right)
\end{aligned}
$$

The amplitudes of the impedances according to the pulse diagrams are shown in the impedance diagrams (see Fig. 7). The maximum values of the spectrum are on resonance frequencies, while the minimum values correspond to anti-resonance frequencies. When the pulse perturbations in the spring coincide with the pulsations of resonance, strain fluctuations are amplified and can cause breakage of the spring.

\section{Applications and results}

The following application illustrates the steps in a frequency response analysis, in which the impedance method

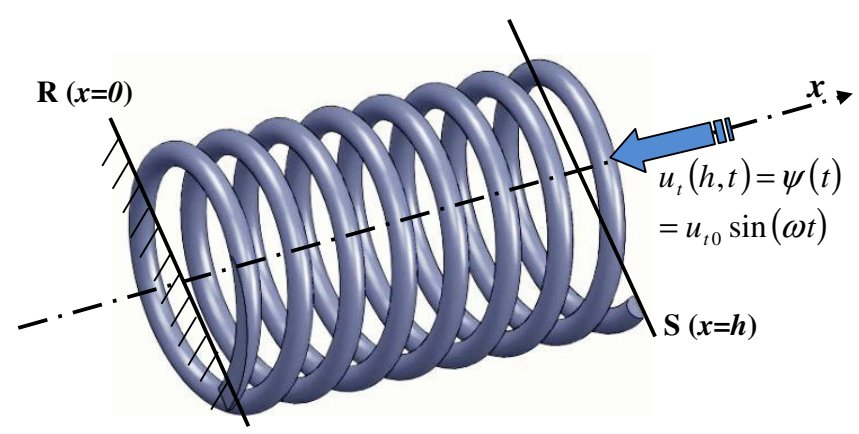

Fig. 6. Ends of the helical spring subjected to axial loading at $x=h$.

is used. The computations needed to evaluate the mechanical impedances at a point in a spring are quite involved when a computer is not used. The general applicability of the method can best be indicated by discussing particular situations. In the following examples the receiving-end impedance of the system is assumed definable by the foregoing relationships, the problem being to determine the impedance at other locations in the compression helical spring.

\subsection{Initial and boundary conditions}

We assume that the spring is initially compressed at a distance $\Delta$ (see Fig. 1). For all $x \in[0, h]$, the initial conditions are defined by:

$$
\begin{array}{r}
u_{x}(x, 0)=-\Delta / h, v_{x}(x, 0)=\theta r / h=0, \quad u_{t}(x, 0)=0 \\
\text { and } v_{t}(x, 0)=0
\end{array}
$$

These conditions satisfy the ordinary differential equation system obtained after having annulled terms $\partial / \partial \mathrm{t}$ in partial differential equations $\{(1 \mathrm{a})$ to $(1 \mathrm{~d})\}$.

We consider a system spring shown in Figure 6. The boundary conditions are expressed by:

$$
u_{t}(0, t)=0, v_{t}(0, t)=0, \text { and } v_{t}(h, t)=0
$$

\subsection{System description}

We consider a compression helical spring from the tamping rammers (see Fig. 8), whose geometric and mechanical characteristics are shown in Table1. 


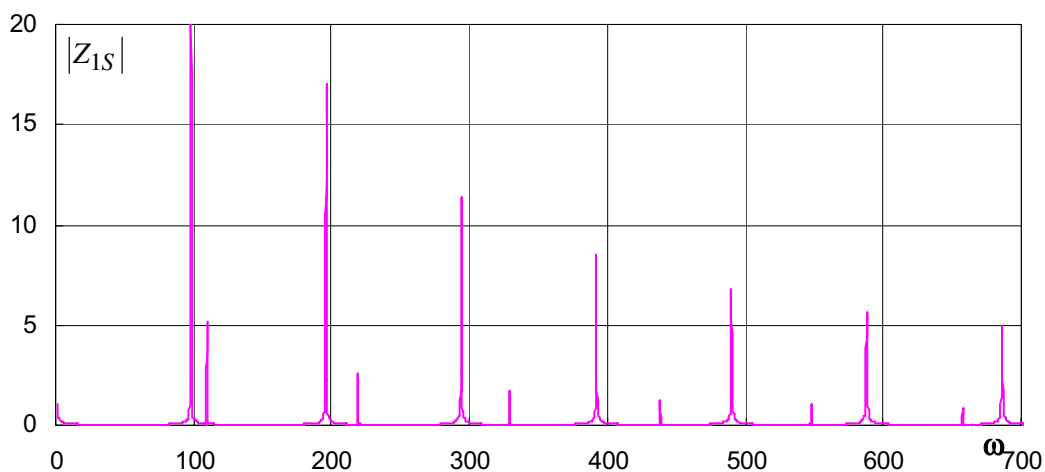

(a) $\mid \mathrm{Z}_{1 \mathrm{~S}} \mathrm{|}=\mathrm{U} x / \mathrm{U} t$

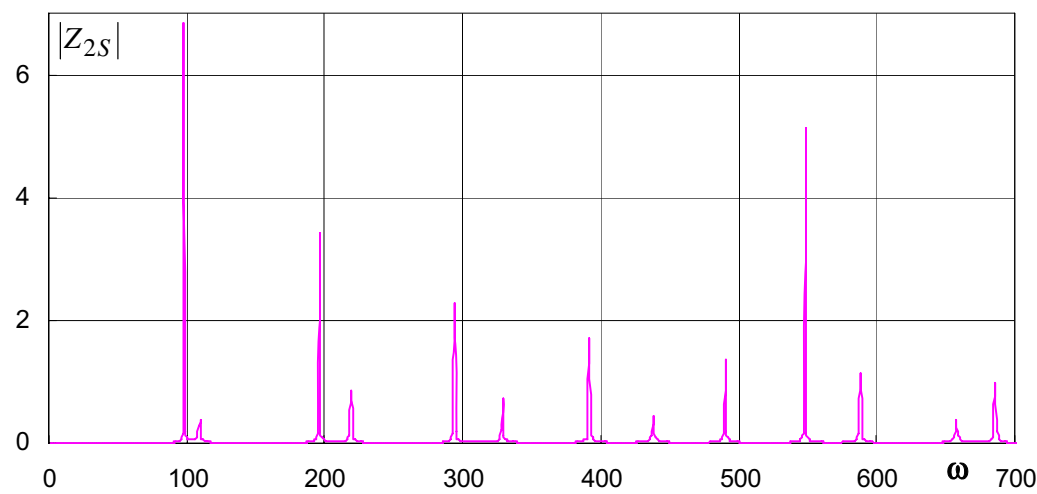

(b) $\left|Z_{2 S}\right|=V x / \mathrm{U} t$

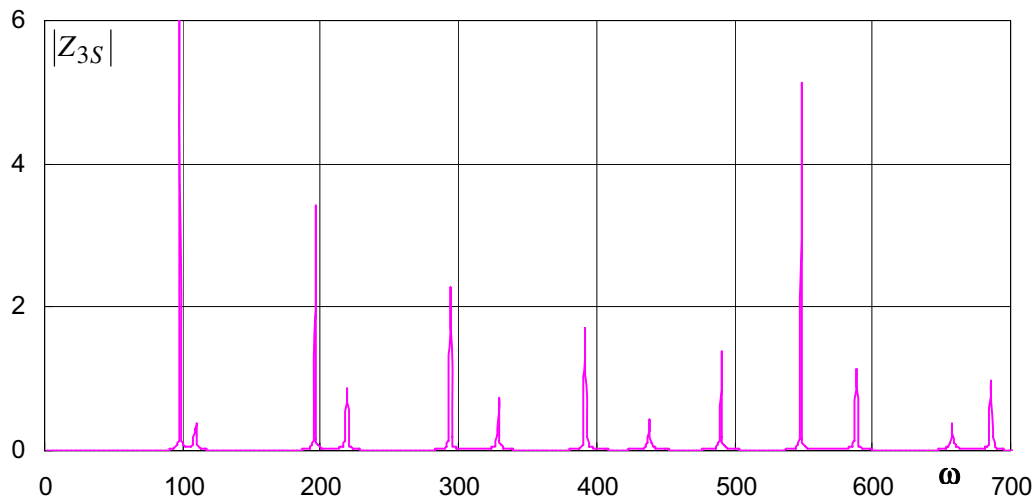

(c) $\mid \mathrm{Z}_{3 \mathrm{~S}} \mathrm{|}=\mathrm{U} x / \mathrm{V} t$

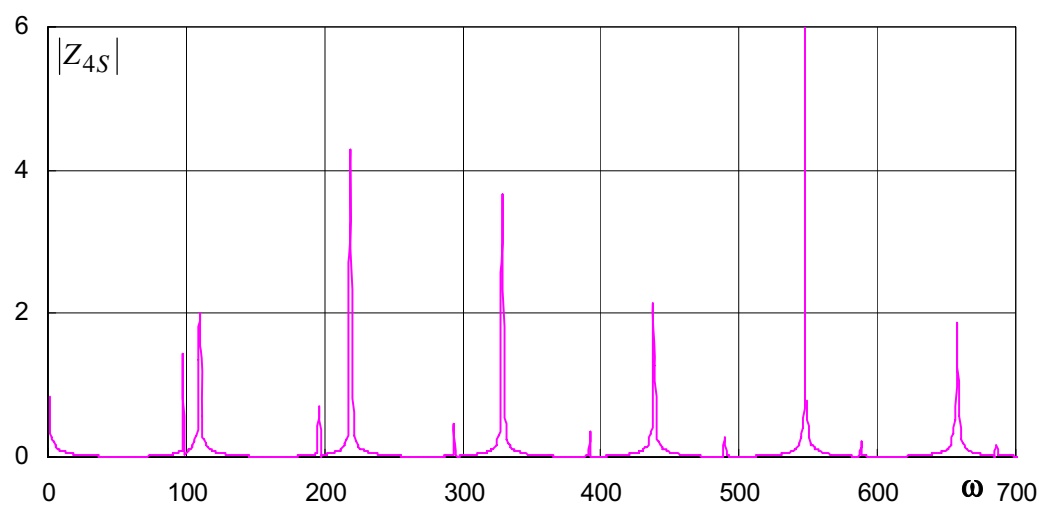

(d) $\mid \mathrm{Z}_{4 \mathrm{~S}} \mathrm{I}=\mathrm{V} x / \mathrm{V} t$

Fig. 7. Impedance diagrams. 


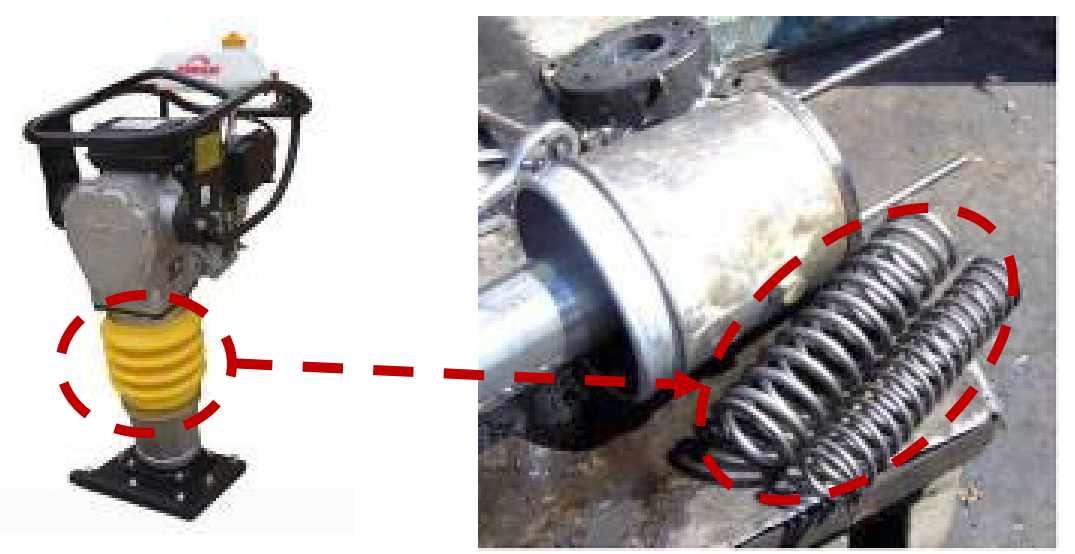

Fig. 8. Helical spring description from tamping rammers.

Table 1. Mechanical and geometric characteristics of the considered springs.

\begin{tabular}{ccc}
\hline Height of the spring & $h$ & $1.1938 \mathrm{~m}$ \\
Helix angle & $\alpha$ & $0.198281 \mathrm{rd}$ \\
Number of turns & $n$ & 6 \\
Poisson's ratio & $v$ & 0.25 \\
Young's modulus & $E$ & $206.85 \mathrm{GPa}$ \\
Shear modulus & $G$ & $81.423 \mathrm{GPa}$ \\
Mass of the spring & $M$ & $2.12868 \mathrm{~kg}$ \\
Radius of the spring & $r$ & $0.157607 \mathrm{~m}$ \\
Wire radius & $r_{f}$ & $0.007 \mathrm{~m}$ \\
Initial compression & $\Delta$ & $0.254 \mathrm{~m}$ \\
\hline
\end{tabular}

A computer program in FORTRAN language is developed that computes the mechanical impedances over a wide range of frequencies $\omega$. In general, the terminal impedances are complex number and can be expressed:

$$
\begin{aligned}
& Z_{1}(h)=Z_{1 R}+i Z_{1 I}=\left|Z_{1}\right| \mathrm{e}^{i \psi_{1}} \\
& \quad \text { and } Z_{2}(h)=Z_{2 R}+i Z_{2 I}=\left|Z_{2}\right| \mathrm{e}^{i \psi_{2}}
\end{aligned}
$$

These impedances vary with frequency and are at their maximum for the infinite number of resonating frequencies. These are the natural frequencies of the helical spring system and, in the case of a spring originating in a clamped extremity, they correspond to fundamental and harmonics. Each natural frequency or resonance, however, is separated on the frequency scale by an anti-resonance, or frequency at which $\left|Z_{1}\right|$ and $\left|Z_{2}\right|$ become small or equal zero.

The impedance diagram provides a very useful aid in assessing the frequency response of a system. The most useful plot is that of the modulus of the impedance versus angular frequency. The impedance diagrams for the helical spring are shown in Figure 7 where the impedance modulus is plotted.

The resonances and anti-resonances are visible as points of high impedance and low impedance, respectively. The fundamental, second, third and fourth harmonics are easily identified as the frequencies associated with large impedances. These frequencies correspond to the maximum impedance modulus values, that is, to the resonance frequencies and are proportional to $C_{s}$ and $C_{f}$, respectively. The two fundamental frequencies are given by:

$$
\begin{aligned}
& \omega_{s}=\frac{\pi C_{s}}{h}=98.035 \mathrm{rd} . \mathrm{s}^{-1} \\
& \quad \text { and } \omega_{f}=\frac{\pi C_{f}}{h}=109.607 \mathrm{rd} . \mathrm{s}^{-1}
\end{aligned}
$$

As indicated in Figure 7, the number series of natural frequencies correspond to the zero of the denominator of $\left|Z_{1}\right|$ and $\left|Z_{2}\right|$, that is the zero of the expression (37). The other natural frequencies are the multiples of $\omega_{s}$ and $\omega_{f}$ :

$$
\begin{array}{r}
\omega_{s k}=k \frac{\pi C_{s}}{h}=98.035 k, \omega_{f k}=k \frac{\pi C_{f}}{h}=109.607 k, \\
k=\begin{array}{llll}
0 & 12 \ldots
\end{array}
\end{array}
$$

\subsection{Resonance and beat phenomena}

The response of the spring in terms of axial and angular deformation following a sinusoidal excitation of the axial velocity to a pulse of resonance or harmonic own anti-resonance is studied for example for the spring shown in Figure 6.

\subsubsection{Excitation with fast frequency $\omega_{f}$}

The numerical results are shown in Figure 9. These figures illustrate the dynamic response represented by the forced vibration of the strains in the spring. This dynamic response in different sections of the spring is due to a sinusoidal excitation of the axial velocity of amplitude $1 \mathrm{~m} . \mathrm{s}^{-1}$ and of pulse corresponding to the fundamental frequency $\omega_{f}=\frac{\pi C_{f}}{h}=109.607 \mathrm{rd} . \mathrm{s}^{-1}$ that is to the faster wave celerity.

The evolutions of axial and rotational strains, as functions of time $t$, are plotted at some sections of the spring: $x=0, x=h / 4, x=h / 2, x=3 h / 4$, and $x=h$. From these results, the strains are maximal at the extremities of the spring. 

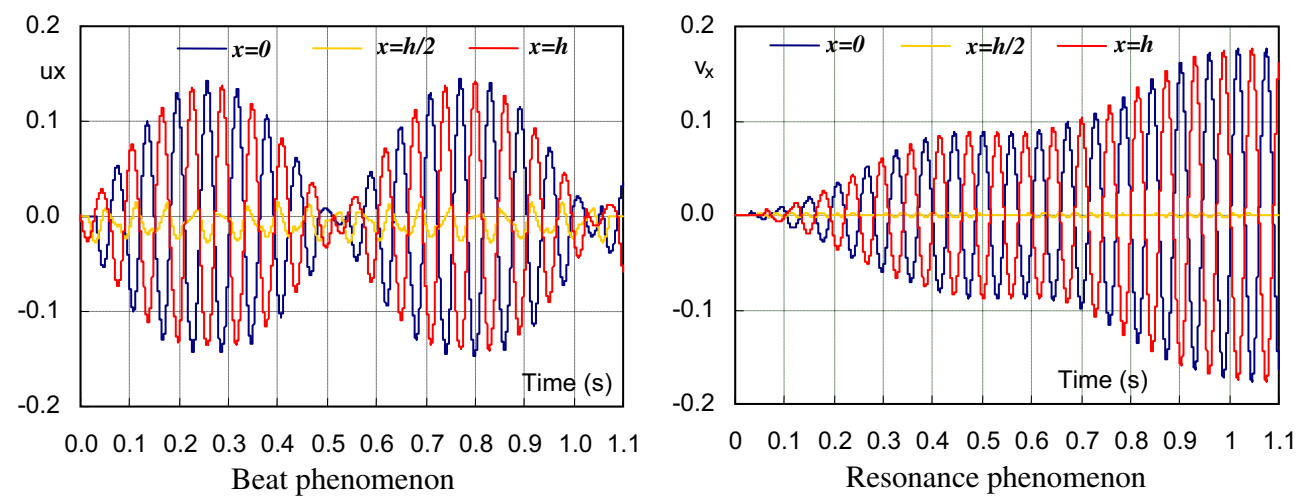

Fig. 9. Evolution of deformation following an excitation at the fast fundamental period $\omega_{f}$.
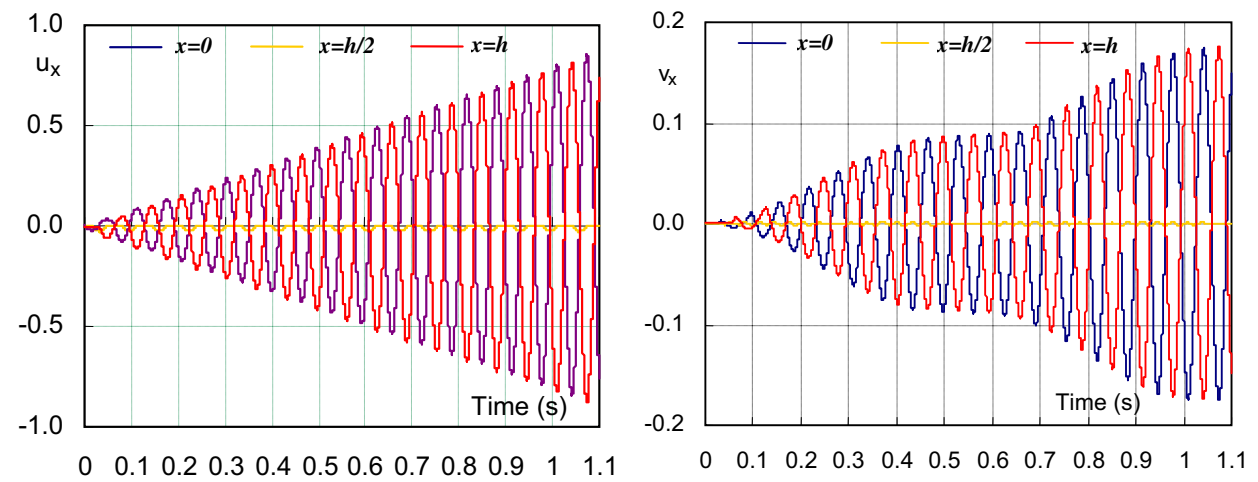

Fig. 10. Evolution of deformation following an excitation at the slow fundamental period $\omega_{s}$.

Note that the resonance phenomenon occurs for the angular deformation, because the pulse $\omega_{f}$ is a fundamental for this mechanical quantity. Therefore, it is amplified continuously until it reaches a steady-oscillatory regime. One can notice that the angular deformation is at its maximum at both ends of the spring. For the axial deformation, a beat phenomenon of waves is rather occuring. Again, the deformation is maximum at both ends of the spring. The observed beat phenomenon develops when two signals of the same type are energized with frequencies close. In this case, the axial velocity of the wave grows with the excitation pulse of $\omega_{f}=109.607{\mathrm{rd} . \mathrm{s}^{-1}}^{-1}$ and the axial strain wave which is excited with the slow pulse $\omega_{s}=98.035 \mathrm{rd} . \mathrm{s}^{-1}$. So, the beat phenomenon reveals two characteristic times:

$$
\begin{aligned}
T_{0}=\frac{4 \pi}{\omega_{s 1}+\omega_{f 1}} & =0.0605 \mathrm{~s} \\
& \text { and } T_{b}=\frac{2 \pi}{\left|\omega_{f 1}-\omega_{s 1}\right|}=0.543 \mathrm{~s}
\end{aligned}
$$

$T_{0}$, which is proportional to the inverse of the mean pulse waves, corresponds to the period of the oscillations of the resulting signal and $T_{b}$, which is proportional to the difference of pulse waves, represents the period of the envelope of these oscillations, that is the period of the beat or of the modulation. Actually, the resonance phenomenon can not be developed for axial waves with fast beat, as they are quickly caught and then destroyed by the angular wave [27]. It can be seen that the resonance phenomenon manifests for rotational strains at all sections only at the middle of the spring $x=h / 2$. For the axial strain, the resonance is reduced to beat phenomenon which takes place between the two waves: the excitation $u_{t}$ which fluctuates at the fast frequency and the axial strain $u_{x}$ which propagates at the slow wave celerity. This can be explained by the fact that the excitation frequency is equal to the fundamental frequency of rapid rotational waves. So the rotational strain resounds. Although the excitation frequency is also a fundamental for the axial strain, the resonance for this strain has not been occurred due the coupling effect and competition of the axial and angular waves.

\subsubsection{Excitation with slow frequency $\omega_{s}$}

Figure 10 shows the evolution of deformation due to a sinusoidal excitation in terms of axial velocity of the natural frequency on the slow speed. The results show that the axial strain is increasing continuously and significantly reflecting the growing phenomenon of resonance in the spring for this quantity. The results also show that the resonance phenomenon expands to the angular deformation. This can be explained by the dynamic coupling between the axial waves and angular waves reflecting the fact that the angular waves are induced in the spring by the axial waves and are never caught by these waves.

However, as shown in Figure 11, the amplification in this case is slightly higher despite the slow frequency 


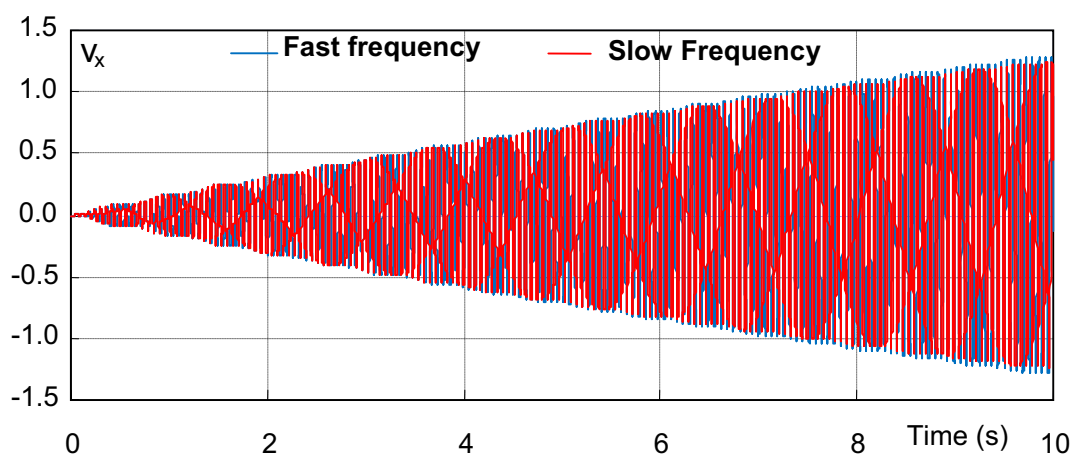

Fig. 11. Evolution of the angular deformation at $x=h$ for two frequencies.
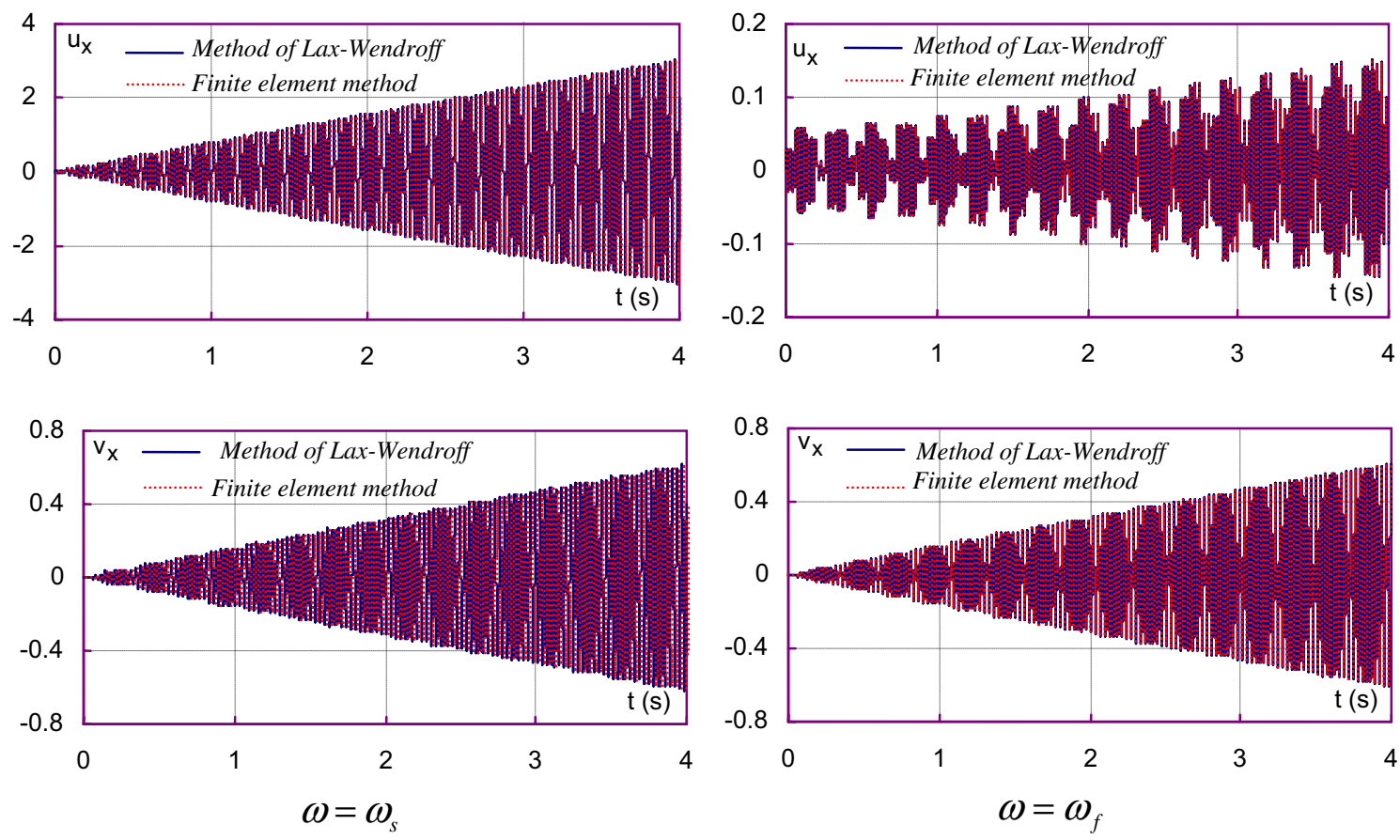

Fig. 12. Validation of the frequency study by the impedance method and comparisons with finite élémnets method (FEM ).

$f_{s}=\frac{1}{T_{s}}=\frac{\omega_{s}}{2 \pi}=15.603 \mathrm{~Hz}$ is smaller than the fast frequency $f_{f}=\frac{1}{T_{f}}=\frac{\omega_{f}}{2 \pi}=17.445 \mathrm{~Hz}$.

\subsection{Comparisons and validation of results}

Computed results obtained, for different frequencies, by this method of the finite differences scheme of LaxWendroff compare favorably well with the numerical results based upon the finite element method in the Figure 12.

This enables validating the results found in this paper. It is clear, that the method of Lax-Wendroff is less expensive than other methods. There is less computer cost involved with this method because of the speed of calculations. This gives an explanation of the difference and novelty of this document comparing to the related existing works.

\section{Conclusion}

This paper investigated resonance and beat phenomena of strains due to forced sinusoidal excitation in helical springs. To study vibrations in helical springs subjected to a sinusoidal excitation, we propose a coupled model. First, the natural frequencies of the spring were predicted by the impedance method. The impedance approach has been used by restricting the solution to the steady-oscillatory case, that is, by assuming harmonic oscillations. In this case, as the behavior of the mechanical variables was governed by a linear system of partial differential equations, the separation of variables technique has been used to develop the mechanical impedances of the spring. Theses impedances vary with frequency and are maximum for the infinite number of resonating frequencies corresponding to fundamental and harmonics. The obtained results permitted to show that the natural frequencies are proportional to the two wave speeds in the spring: the slow axial wave speed and the rapid rotational 
wave speed. Next, the evolution of axial and rotational strains, at various sections of the spring, due to an axial velocity harmonic excitation, was analysed and the phenomena of resonance and beat was illustrated. Numerical solutions were obtained by the Lax-Wendroff scheme when the vibrations were caused by harmonic forced axial velocity. As there were two different sets of natural frequencies, because of the two different waves that propagated through the spring, the dynamic behaviour of the strains was conditioned by the wave that matched the frequency of the excitation when resonance occurred. In this sense, numerical results showed that the axial and rotational strains resonated and followed the excitation for slow frequencies. The amplification was more important for the axial strain than for the rotational one which was induced by the effect of Poisson coupling. Numerical results of the example studied and simulated, have been confronted with such physical explanations regarding the dynamic coupling between the axial and angular waves and the phenomena of wave reflections on both ends of the spring. For excitation with rapid natural frequencies, the resonance occurred only for rotational strains and the beat phenomenon was observed for axial strain.

\section{References}

[1] A.M. Wahl, Mechanical springs, Cleveland, Ohio, Penton Publishing Co., 1963

[2] W.H. Wittrick, On elastic wave propagation in helical springs, Int. J. Mech. Sci. 8 (1966) 25-47

[3] A.E.H. Love, A treatise on the mathematical theory of elasticity, 4th Editions, Dover Publications, New York, 1927

[4] V.K. Stokes, On the dynamic radial expansion of helical springs due to longitudinal impact, J. Sound Vib. 35 (1974) 77

[5] B. Gironnet, G. Louradour, Comportement dynamique des ressorts, Techniques de l'Ingénieur BD2 (1983) B6101-B610-11

[6] V. Yildirim, An efficient numerical method for predicting the natural frequencies of cylindrical helical springs, Int. J. Mech. Sci. 41 (1999) 919-939

[7] J. Lee, D.J. Thompson, Dynamic stiffness formulation, free vibration and wave motion of helical springs, J. Sound Vib. 239 (2001) 279-320

[8] L. Lee, Free vibration analysis of cylindrical helical springs by the pseudo spectral method, J. Sound Vib. 302 (2007) 185-196

[9] L.E. Becker, G.G. Chassie, W.L. Cleghorn, On the natural frequencies of helical compression springs, Int. J. Mech. Sci. 44 (2002) 825-841
[10] W. Jiang, T.L. Wang, W.K. Jones, The forced vibration of helical spring, Int. J. Mech. Sci. 34 (1992) 549-563

[11] S.K. Sinha, G.A. Costello, The numerical solution of the dynamic response of helical springs, Int. J. Numeri. Methods Eng. 12 (1978) 949-961

[12] J.W. Phillips, G.A. Costello, Large deflections of impacted helical springs, J. Acoust. Soc. America 51 (1971) 967-972

[13] S. Ayadi, E. Hadj-Taieb, G. Pluvinage, The numerical solution of strain waves propagation in elastic helical springs, Mater. Technol. (2007) 47-52

[14] S. Ayadi, E. Hadj-Taïeb, Influence des caractéristiques mécaniques sur la propagation des ondes de déformations linéaires dans les ressorts hélicoïdaux, Mécaniques et Industries 7 (2006) 551-563

[15] S. Ayadi, E. Hadj-Taïeb, Simulation numérique du comportement dynamique linéaire des ressorts hélicoïdaux, Trans. Can. Soc. Mech. Eng. 30 (2006) 191-208

[16] A. Lerat, R. Peyret, Sur le choix des schémas aux differences du second ordre fournissant des profils de choc sans oscillations, C.R. Acad. Sci. Paris 277 (1966) 363-366

[17] P.D. Lax, B. Wendroff, Difference schemes for hyperbolic equations with high order of accuracy, Communi. Pure Appl. Math. 17 (1966) 381-398

[18] G.R. Buchanan, Finite Element Analysis, Tata McGrawHill Edition, New Delhi, 2004

[19] D.H. Norrie, G. Vries, The Finite Element Method, Acadamie Press Inc., New York, 1973

[20] C. Zienkiewicz, R.L. Taylor, The Finite Element Method, The fourth edition, McGraw-Hill Book Company, U.K., 1988

[21] G. Dhatt, G. Touzot, Une présentation de la méthode des éléments finis, Ed. Maloine SA, Paris, 1984

[22] F. Scheid, Numerical Analysis, Second Edition, Tata McGraw-Hill Edition, New Delhi, 2004

[23] R. Courant Freidrichs, K.H. Lewy, Uber die Partiellen Differenzengleichungen der Mathematischen Physick, Math. Annaen 100 (1928) 32-74

[24] R.D. Richtmeyer, K.W. Morton, Difference methods for initial value problems, Intersciences Publishers, A Division of Jhon Wylie and Sons, New York, 1967

[25] V. Yildirim, Expressions for predicting fundamental natural frequencies of non-cylindrical helical springs, J. Sound Vib. 252 (2002) 479-491

[26] C.E. Fröberg, Introduction to numerical analysis, AdisonWesley Publishing Company, USA, 1979

[27] S. Ayadi, E. Hadj-Taieb, Finite element solution of dynamic response of helical springs, Int. J. Simul. Modell. 7 (2008) $17-28$ 